\title{
Study of Technological Parameters Serrated Moving Front of Mining Operations
}

\author{
Viktor E. Kislyakov and Pavel V. Katyshev* \\ Siberian Federal University \\ 79 Svobodny, Krasnoyarsk, 660041, Russia
}

Received 03.12.2014, received in revised form 01.02.2015, accepted 20.02.2015

This article presents the results of technological solutions and their parameters to ensure efficiency of mining on the gently sloping fields with fan-moving front of mining operations.

Keywords: fan Chart displacement of the front, blanket deposit streaming technology, coal.

\section{Исследование технологических параметров при веерном подвигании фронта горных работ}

\author{
В.Е. Кисляков, П.В. Катышев \\ Сибирский федеральнылй университет \\ Россия, 660041, Красноярск, пр. Свободный, 79
}

В данной статье приведены результать технологических решений и их параметров, обеспечивающие повышение эффективности разработки полезных ископаемых на пологопадающих месторождениях при веерном подвигании фронта горных работ.

Ключевые слова: веерное перемещуение фронта, пластовое месторождение, поточная технология, уголь.

За последние 10 лет мировое потребление угля выросло почти на 50 \% (потребление газа примерно на 30 \%; нефти и атомной энергии - менее чем на 10 \%). Уголь - это один из главных источников энергоресурсов, способен удовлетворить основные энергетические потребности растущего населения и развивающейся мировой экономики, внести важнейший вклад в преодоление энергетической бедности и энергетического неравенства.

Конкурентные преимущества российской угольной отрасли в рамках отечественного ТЭК заключаются в наличии огромных (второе место в мире) запасов угля, которых при существующем уровне добычи хватит на 600 лет; значительном опыте использования данного энергоресурса; повышении устойчивости энергоснабжения (в том числе в кризисных ситуациях);

C) Siberian Federal University. All rights reserved

* Corresponding author E-mail address: bestpavel1989@mail.ru 
возможностях выхода на мировой рынок; наличии существенных резервов повышения эффективности; многообразии различных видов угольной продукции; возможностях адаптации к меняющимся условиям рынка; интеграции с приоритетными направлениями инновационного развития экономики; вкладе в региональную энергетическую безопасность.

Вышеизложенное ставит перед угольной промышленностью вопросы по решению задач модернизации предприятий и развитию новых технологий в добыче угля для снижения издержек и повышения эффективности в производстве.

При разработке открытым способом пологопадающих и горизонтальных пластов крупных по запасам и площадям угольных месторождений с применением поточной технологии на основе выемочно-погрузочных комплексов (экскаваторов) существенное влияние на эффективность добычи угля оказывает выбор направления перемещения (развития) фронта горных работ в карьере.

В отечественной и мировой практике известны четыре схемы: параллельного, веерного, радиального и комбинированного перемещения фронта работ в технологии поточной добычи угля. Наиболее распространенной и простой по конструкции является параллельная схема, однако её применение сопровождается постоянным наращиванием и перестройкой транспортных коммуникаций.

В этой связи были проведены исследования технологических параметров поточной добычи угля при веерном подвигании фронта горных работ, причем к достоинствам данного способа подвигания можно отнести исключение необходимости постоянного наращивания транспортных коммуникаций и стабилизацию расстояния транспортировки полезного ископаемого [1].

В мире известны угледобывающие предприятия, на которых успешно применяется веерное подвигание фронта работ или комбинация параллельного и веерного способов одновременно с поточной технологией. К таким объектам относится угледобывающее предприятие «Гарцвайлер» в Германии. Принципиальная схема подвигания фронта работ на разрезе представлена на рис. 1.

В проекте предприятия продолжить разработку карьера «Гарцвайлер II» также с применением веерного подвигания фронта горных работ с 2025 г. до завершения отработки месторождения в 2044 г., что доказывает ее актуальность ссылкой на проектный чертеж схемы подвигания фронта работ (рис. 2).

Как видно из схем, на угольных разрезах применяется комбинированное (параллельновеерное) перемещение фронта работ с одним или несколькими поворотными пунктами. Выбор направления подвигания фронта горных работ определяется параметрами тела полезного ископаемого, конфигурация которого позволяет отрабатывать запасы веерным способом.

Принципиальная схема веерного подвигания фронта при работе выемочно-погрузочного комплекса непрерывного действия представлена на рис. 3.

Однако на пологопадающих месторождениях прямоугольной формы при использовании веерной системы разработки неизбежно остаются целики полезного ископаемого, для их устранения был предложен следующий технологический прием.

Одновременно с веерным подвиганием фронта горных работ следует отрабатывать целики полезного ископаемого выемочно-погрузочным комплексом цикличного действия (рис. 4). Вы- 


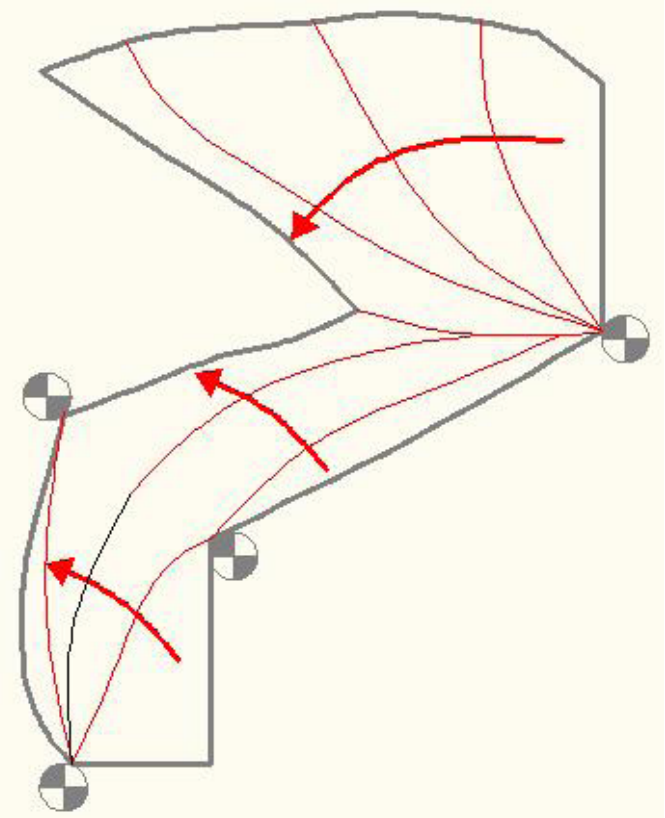

Рис. 1

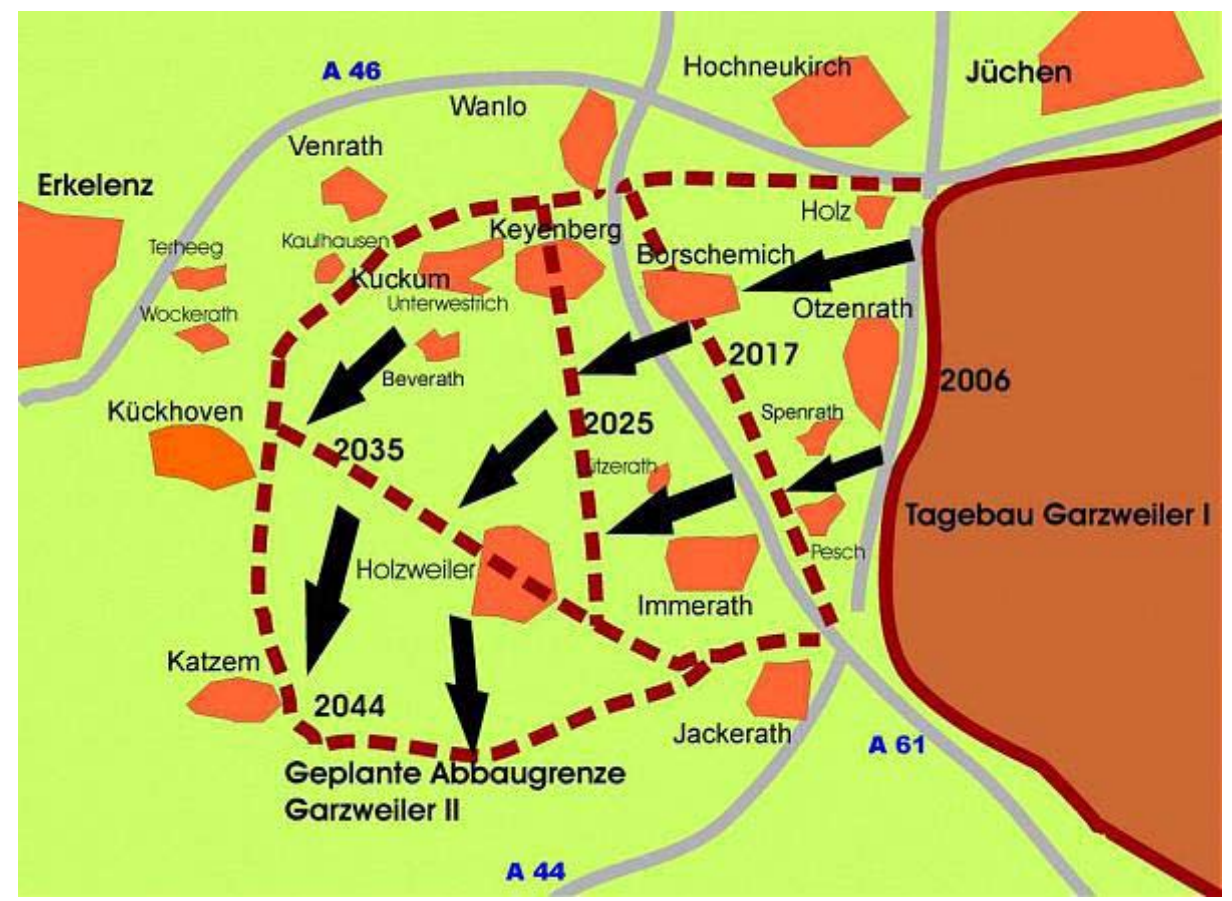

Рис. 2 


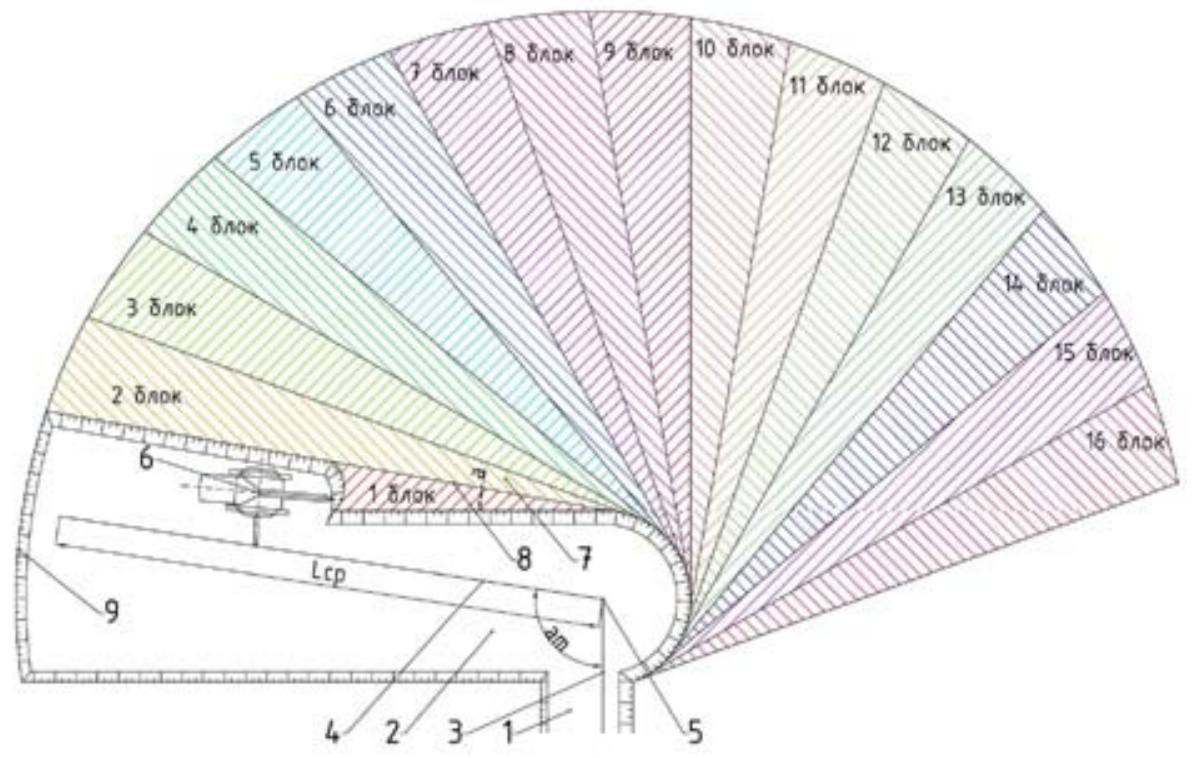

Рис. 3

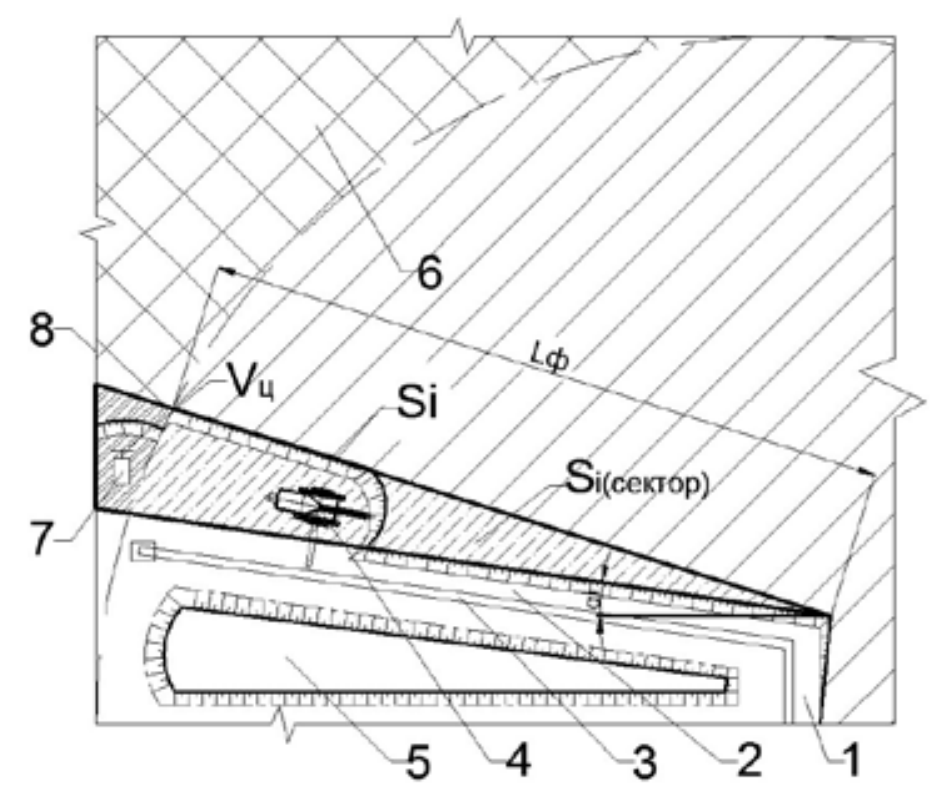

Рис. 4

емка целиков осуществляется в границах карьерного поля с отгрузкой породы на совместные транспортные коммуникации и складированием пустой породы в отвал.

На рис. 4 видно, что при развитии веерной системы происходит изменение объема целика полезного ископаемого. Следовательно, при планировании горных работ, а также для равномерного подвигания фронта горных работ при веерной системе разработки с отработкой целиков целесообразно определить объем целика полезного ископаемого, вынимаемого техникой 


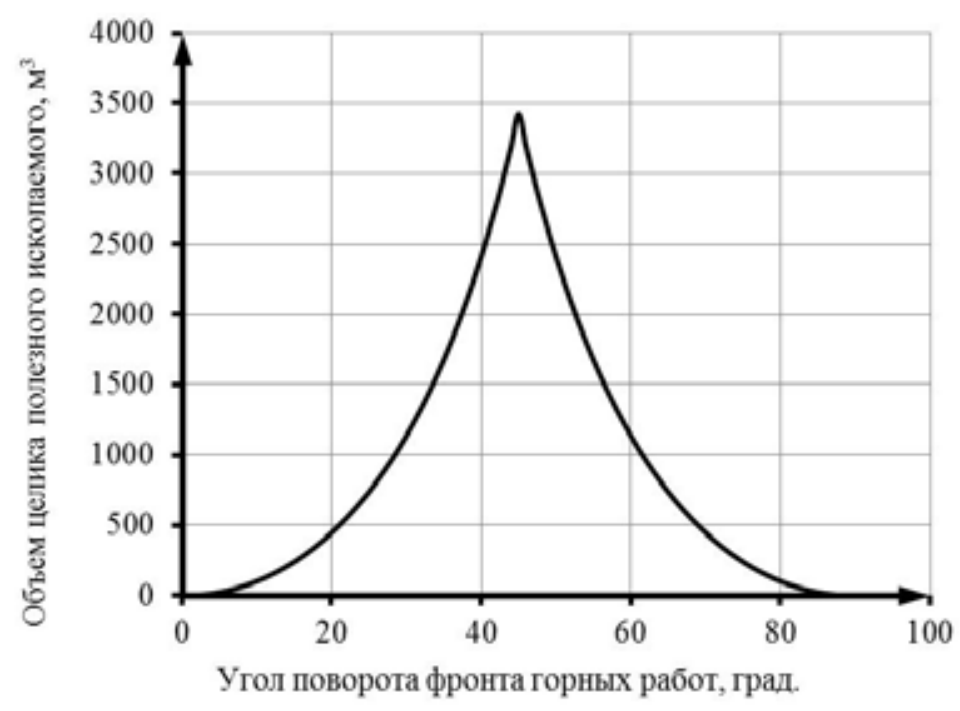

Рис. 5

цикличного действия, а также изменения объема вынимаемого целика от угла поворота фронта горных работ.

Первоначально определяем площадь клиновидной заходки:

$$
\mathrm{S}_{\mathrm{i}(\text { сектор })}=\frac{\pi \cdot \mathrm{L}_{\Phi}^{2} \cdot \alpha_{\mathrm{i}}}{360},
$$

где $\mathrm{L}_{\Phi}$ - длина фронта работ, м; $\alpha_{\mathrm{i}}-$ угол поворота фронта работ, град.

Продлевая линию контура клиновидной заходки до границы карьерного поля, образуем треугольник $\mathrm{S}_{\mathrm{i}}$ (площадь клиновидной заходки и целика полезного ископаемого, $\mathrm{M}^{2}$ ), его площадь определяем по формуле

$$
\mathrm{S}_{\mathrm{i}}=\frac{\mathrm{L}_{\Phi}^{2} \cdot \operatorname{tg}\left(\sum_{\mathrm{i}=1}^{\mathrm{n}} \alpha_{\mathrm{i}}\right)}{2}
$$

где $\mathrm{L}_{\Phi}$ - длина фронта работ, м; $\alpha_{\mathrm{i}}$ - угол поворота фронта работ, град; $\mathrm{n}$ - количество клиновидно эксплуатационных блоков.

Объем целика полезного ископаемого определяем из следующего неравенства:

$$
\mathrm{V}=\mathrm{H} \cdot\left(\mathrm{S}_{\mathrm{i}}-\mathrm{S}_{\mathrm{i}-1}-\mathrm{S}_{\mathrm{i}(\text { сектор) })}\right),
$$

где $\mathrm{H}$ - средняя мощность полезного ископаемого, м.

С учетом данных уравнений была выведена математическая зависимость изменения объёма целика полезного ископаемого от угла поворота фронта горных работ (рис. 5).

Из рис. 5 видно, что с увеличением угла поворота фронта горных работ возрастает площадь целика полезного ископаемого. Максимальный показатель объёма целика достигается при угле поворота фронта горных работ в $45^{\circ}$ и при дальнейшем развитии уменьшается; это 
позволяет планировать распределение мощности выемочно-погрузочного комплекса цикличного действия, что, в свою очередь, определяет снижение трудоёмкости, повышение эффективности, рациональное извлечение полезного ископаемого и безопасное ведение горных работ. Вышеизложенное доказывает необходимость разработки технологических приемов, обеспечивающих эффективную выемку полезных ископаемых при веерной системе разработки.

\section{Список литературы}

[1] Шорохов В.П., Кисляков В.Е. Веерное подвигание фронта работ при разработке мощных угольных пластов. LAP LAMBERT Academic Publishing 2012. 77 с. 